\title{
SEMINARIOS REGIONALES O INTERDIOCESANOS
}

DOI: https://doi.org/10.52039/seminarios.v63i219.93

MANUEL SÁNCHEZ MONGE*

No podemos hablar de este tema sin tener en cuenta las aportaciones del nuevo documento de la Congregación para el Clero, El don de la vocación presbiteral. Ratio fundamentalis institutionis sacerdotalis (2016), donde se ofrecen las líneas fundamentales de la formación de los futuros sacerdotes para toda la Iglesia. Por una parte, actualiza los documentos de la Iglesia en este tema, especialmente la anterior Ratio de 1970, actualizada en 1985, y la Exhortación apostólica Pastores dabo vobis del papa Juan Pablo II, de 1992. Y por otra, recoge las experiencias positivas surgidas desde entonces y las nuevas metodologías, afrontando también nuevas realidades.

Teniendo como referencia la nueva Ratio, las Conferencias Episcopales elaborarán la Ratio nationalis y el obispo diocesano (o los obispos interesados, en el caso de un Seminario interdiocesano), ayudados por el equipo de formadores del Seminario, tienen el deber de elaborar un proyecto de «formación integral», también denominado itinerario formativo. Dicho itinerario habrá de tomar en consideración el origen cultural de los seminaristas, la pastoral de la diócesis y la propia «tradición formativa» de la Iglesia particular, además de promover su aplicación práctica, respetando las diversas etapas y el proceso pedagógico correspondientes (Ratio 10).

\section{EL PROCESO FORMATIVO}

El proceso formativo que se contempla en la nueva Ratio no sólo tiene en cuenta la formación inicial, sino también la formación permanente y la pastoral vocacional.

* Es obispo de Santander. Anteriormente desempeñó el cargo de rector del Seminario Mayor de la diócesis de Palencia. 
La formación inicial se articula en fases: propedéutica (necesaria y obligatoria), discipular (filosofía), configuradora (teología) y pastoral.

La formación ha de ser única, integral, comunitaria y misionera, es decir, ha de abarcar todas las dimensiones de la persona: humana, espiritual, intelectual y apostólica. La vida espiritual es absolutamente fundamental, sin ella todo lo demás sobra. Y el mundo afectivo está incluido en la formación humana y en la vida espiritual. Son dos elementos que se tienen que integrar. Los buenos afectos han de ser integrados en quien ha de tener corazón de pastor para el bien del pueblo de Dios.

El Seminario es una comunidad formativa. Si la vida comunitaria es muy importante en el desarrollo de cada persona, lo es especialmente en quienes se preparan para el sacerdocio ministerial: no se trata sólo de que los seminaristas que conviven se lleven bien, es preciso además que tomen conciencia de que se nace en una comunidad familiar, se crece en el seno de una comunidad cristiana parroquial, se forma en la comunidad del Seminario y vivirá su sacerdocio dentro de una comunidad sacerdotal que es el presbiterio diocesano. En comunidad se puede vivir la alegría de la amistad y la corrección fraterna, que son muy necesarias para el futuro sacerdote.

«Esta formación tiene un carácter eminentemente comunitario desde su mismo origen. La vocación al presbiterado, de hecho, es un don de Dios a la Iglesia y al mundo, es una vía para santificarse y santificar a los demás, que no se recorre de manera individual, sino teniendo siempre como referencia una porción concreta del pueblo de Dios. Tal vocación es descubierta y acogida en el seno de una comunidad, se forma en el Seminario, en el contexto de una comunidad educativa que incluye a los diversos componentes del pueblo de Dios, para que el seminarista, mediante la ordenación, llegue a formar parte de la «familia» del presbiterio, al servicio de una comunidad concreta.

También, respecto a los sacerdotes formadores, la nueva Ratio pretende subrayar que, para asegurar la eficacia en el ejercicio de sus funciones, deben considerarse y actuar como una verdadera comunidad formativa, la que comparte una única responsabilidad, respetando las competencias y el encargo encomendado a cada uno.

Dado que el discípulo sacerdote proviene de la comunidad cristiana y a ella regresa para servirla y guiarla en calidad de pastor, la formación se caracteriza naturalmente por el sentido misionero, pues tiene como finalidad la participación en la única misión confiada por Cristo a su Iglesia: la evangelización en todas sus formas» (Ratio 3 ). 
Hay que prestar particular atención al hecho de que hoy día entran en el Seminario candidatos adultos. Esto no aporta sólo mayor madurez y más clara decisión vocacional, sino que a veces cuentan con un pasado de largos años sin práctica religiosa y con muchas heridas de carácter afectivo. Por todo ello necesitan un mayor acompañamiento para discernir si es o no auténtica la llamada que sienten para ser sacerdotes. Es necesario discernir las razones y/o los impulsos que le han llevado a elegir un camino del que estaban muy alejados. Limar lo que haya de afectos desorientados y evitar sublimaciones que pueden resultar peligrosas en el ejercicio del ministerio. Por esta y otras razones es imprescindible el Curso Propedéutico.

Ahora bien, ¿es posible iniciar un curso de esta importancia con apenas dos o tres candidatos? ¿Sería verdaderamente enriquecedor? Pienso que es necesario el contraste con otras vidas que, partiendo de diversa dinámica, han llegado a desembocar en el mismo deseo y en el sentimiento de que son llamados al ministerio presbiteral. Como decía más arriba, es preciso descubrir si hay heridas afectivas, de qué tipo y la posible terapia. El bien de las comunidades se juega en esta seriedad en el discernimiento y en el proceso que sigan una vez aceptados en el seminario. De ninguna manera se trata de desconfianza, sino de querer la felicidad para ellos en su madurez afectiva, y también para la comunidad a la que se preparan a servir y acompañar en el camino de la fe.

2. Formar SACERDOtES PARA LA NUEVA ETAPA EVANGELIZADORA QUE ESTAMOS VIVIENDO

Ya en Pastores dabo vobis Juan Pablo Il exhortaba a formar presbíteros «que sean ministros convencidos y fervorosos de la nueva evangelización, servidores fieles y generosos de Jesucristo y de los hombres» (PDV 10). Y añadía: «Hoy, en particular, la tarea pastoral prioritaria de la nueva evangelización, que atañe a todo el pueblo de Dios y pide un nuevo ardor, nuevos métodos y una nueva expresión para el anuncio y el testimonio del Evangelio, exige sacerdotes radical e íntegramente inmersos en el misterio de Cristo y capaces de realizar un nuevo estilo de vida pastoral» (PDV 18). Si no están convencidos de que Jesucristo y su Evangelio es lo más importante que se puede ofrecer al hombre de hoy, no podrán ser evangelizadores; más aún, se plegarán dócilmente a los postulados de la cultura dominante y llevarán una vida caracterizada por el consumismo, el materialismo y el narcisismo de las sociedades ricas en las que viven. 
Si algo de positivo tiene la actual crisis de vocaciones es que la decisión de seguir a Jesús en el ministerio presbiteral no es fácil que esté motivada por el deseo de «ascender» de estatus social, ni por las ganancias económicas que reporte; de hecho, sabemos que las gratificaciones a los sacerdotes están muy lejos de la fantasía popular que imagina que son los más ricos. Quizás lo que sí es cierto es que la mayoría de los sacerdotes necesitan bastante poco para sentirse satisfechos. Por consiguiente, los motivos económicos no son el incentivo para seguir al Señor en el ministerio sacerdotal.

Ahora bien, el auténtico sentido que impulsa ese deseo generoso tiene que partir de una auténtica experiencia de Jesús, de haber sentido su mano acariciando el corazón, a veces destrozado de jóvenes sin horizonte válido en su vida, que se han llenado de la ilusión de estar preparados para... servir a los hermanos en la Nueva Evangelización «con nuevo ardor, nuevos métodos y una nueva expresión para el anuncio y el testimonio del Evangelio». Se trata, por lo tanto, del sacerdote testigo, aquel que es capaz de decir con el evangelista Juan: «Lo que hemos visto y oído respecto al Verbo de la vida».

\section{Seminarios REgIONALES}

Comencemos recordando las recomendaciones de la Ratio: «Donde lo permitan las circunstancias o donde tales experiencias ya se realicen, se alienta la institución de organizaciones supradiocesanas de Seminarios. Estos organismos pueden representar una gran ayuda como instrumentos de consulta para la comunicación y la colaboración entre los formadores de los diversos Institutos, favoreciendo el análisis de las experiencias educativas y didácticas, y su desarrollo más homogéneo en el ámbito regional, o un mayor intercambio en el internacional.

Como miembros de tales organismos serán convocados los formadores de los diversos Institutos. Es importante que estas organizaciones actúen bajo la guía de la Comisión de la Conferencia Episcopal para el Clero y los Seminarios. En cada caso, en espíritu de comunión eclesial, corresponde a la Congregación para el Clero erigir eventuales organizaciones a nivel universal, mientras a las Conferencias Episcopales o a las diversas organizaciones de las mismas (por ejemplo, el Consejo Episcopal Latinoamericano, el Consilium Conferentiarium Episcoporum Europae, la Federation of Asian Bishops' Conferences, etc.) les corresponde, después de haber consultado a este Dicasterio, la erección de las organizaciones 
continentales y de aquellas que operan dentro de su territorio, aprobando sus estatutos y respetando la competencia de los Obispos diocesanos y de las Conferencias Episcopales.

Tenemos muy en cuenta las reservas que algunos prelados a este tipo de centros en los que se puede perder la esencia de la propia diocesaneidad, porque es cierto que el que se prepara para incorporarse a un presbiterio debe entrar cuanto antes en contacto con el mismo. Sólo así irá superando prejuicios, sabiendo dónde está los puntos positivos y dónde los negativos, los tics, los objetivos, los medios para ejercer una pastoral actual y conocedora del terreno en el que se desenvuelve, etc. Pero no lo es menos el que una formación sin perspectivas universales no es fácil que se consiga si la persona no tiene la posibilidad de contraste con jóvenes (o menos jóvenes, pero que están en su punto de dinámica formativa) con sus características personales que siempre enriquecen por afinidad o por contraste.

Como ya sucede en algunas regiones, podrá ser de gran utilidad que dichas organizaciones promuevan cursos para los formadores y actividades de estudio y reflexión sobre temas relacionados con la vocación y la formación presbiteral en el territorio de su competencia, ofreciendo los resultados a las Conferencias Episcopales interesadas» (Ratio 9).

Quizá pueda ser altamente positivo desarrollar la etapa propedéutica con carácter interdiocesano. La riqueza de un grupo relativamente numeroso en la formación no es desdeñable a la hora de decidir marco educativo. Estamos convencidos y lo reiteramos una vez más, del poder educador de la convivencia y la maduración integral que la misma facilita. Cierto que precisa de la sinceridad y la confianza entre ellos y con los encargados de acompañarles en la formación. No obstante, siempre que se pueda contar con una comunidad formativa y con formadores adecuadamente preparados es bueno mantener el Seminario en la propia diócesis, allí ha de desarrollarse su misión y encarnarse cada vez más en la realidad cultural, religiosa, en los valores propios, con un conocimiento experiencial del terreno en el que han de sembrar y cultivar la Palabra, por eso lo ideal es que hubiese comunidades en los seminarios que puedan ser educativas. Por esa razón sólo cuando el escaso número de seminaristas impida tener un Seminario que sea una auténtica comunidad formadora es recomendable, si no necesario, trasladar los seminaristas fuera de la diócesis. Pero siempre sin perder el contacto frecuente con la realidad en la que ejercerán su ministerio. 


\section{a) Fortalezas del Seminario Regional o Interdiocesano}

Estos organismos pueden representar una gran ayuda, «como instrumentos de consulta para la comunicación y la colaboración entre los formadores de los diversos Institutos, favoreciendo el análisis de las experiencias educativas y didácticas y su desarrollo más homogéneo en el ámbito regional, o un mayor intercambio en el internacional» (Ratio 9).

Como ya sucede en algunas regiones, podrá ser de gran utilidad que dichas organizaciones promuevan cursos para los formadores y actividades de estudio y reflexión sobre temas relacionados con la vocación y la formación presbiteral en el territorio de su competencia, ofreciendo los resultados a las Conferencias Episcopales interesadas (Ratio 9). Importante que los formadores tengan un punto de arranque común y, conservando las peculiaridades de los seminaristas en razón de su origen, de las características de sus respectivas diócesis, actuar de consuno en lo que es nuclear en el proceso formativo: la madurez humano-afectiva, social (convivencia, apertura, trato amable y disponibilidad junto con actitud y acción de servicio y de colaboración) y espiritual, posiblemente la que tiene que aglutinar los demás aspectos de esta maduración y también su proceso.

Entre lo que pudiéramos Ilamar «fortalezas» de los Seminarios regionales se pueden enumerar las siguientes:

-Mayor nivel académico en cuanto a preparación de profesores, mantenimiento de una biblioteca bien dotada, mayor exigencia en el nivel intelectual, etc. En un Seminario con pocos alumnos el estímulo para la formación intelectual, incluso la motivación de los profesores, es bajo. Corre el peligro de dedicarse a una seudoactividad pastoral que responde más a sus «preferencias» que a la formación en ese aspecto tan necesaria.

- Más rica convivencia al formar la comunidad educativa del Seminario un número mayor de seminaristas, oriundos de diversas diócesis. Es este un punto importante, ya que ayuda mucho a que el seminarista capte la realidad universal de la Iglesia, el sentido de diocesaneidad se amplía a las diócesis cercanas y sintonizan unos con los problemas de los otros, incluso puede ser motivo de animarse mutuamente al constatar que, con pocas diferencias, se parecen mucho los de unos y los de otros (de sus respectivas diócesis) y abrirse a un diálogo y actitud de cooperación en la propia formación y la del grupo del que forman parte. Contribuye, además, a obviar un problema de aldeanismo diocesano, con más peligro cuantos menos seminaristas sean en una diócesis. 
El Seminario regional contribuye, por lo tanto, a abrir la visión de la vida de los seminaristas superando una visión provinciana de la misma. La perspectiva desde el Seminario regional ha de ser enriquecedora, ya que se suman experiencias diferentes y, a la vez, una misma misión con los matices peculiares de cada zona.

Un Seminario regional permite lograr un mejor Equipo de formadores y profesores, si tiene en cuenta que ha de conjuntarse como un solo equipo formativo, sin distingos por origen, ni por importancia de la diócesis, habida cuenta de que en el tema de la Evangelización son preferidos los más pobres y necesitados; no en vano, todos los que forman la Iglesia son un solo pueblo, camine en la diócesis que camine. Para esto, es decir, para ser pastor al ejemplo del Buen Pastor, se prepara el presbítero.

\section{b) Debilidades del Seminario Regional}

El Seminario Interdiocesano o Regional dificulta la presencia de los seminaristas en algunos acontecimientos importantes de la diócesis a la que pertenecen. Por lo cual, uno de los puntos importantes para la inserción en la realidad en la que están llamados a trabajar es el de formalizar un calendario que sin ser impedimento para conseguir las bondades del Seminario Regional, esté abierto a la participación en dichos acontecimientos importantes.

Suele provocar demasiado aprecio por los títulos académicos y menos preparación en algunas asignaturas directamente relacionadas con el trabajo pastoral. También depende de la actitud y el planteamiento que se haga entre los ordinarios de las diócesis respectivas y el equipo de formadores. Hay que potenciar el crecimiento en esos valores sacerdotales y en su ir identificándose progresivamente en ellos: la configuración con Cristo, la madurez humana, el dominio y manejo de los sentimientos, la capacidad de trabajo y apertura.

El Obispo diocesano apenas influye en el Plan de estudios y en la marcha del Centro académico. Aunque también es una debilidad subsanable, no deja de ser importante. Para que se soslaye tal posibilidad negativa es preciso que exista un acuerdo en las materias y la dinámica de los años de estudio, tomando como base el plan de estudios que sugiere la Ratio y acomodarlo a las necesidades concretas comunes y diferentes. Se podría incluso hacer un plan completo con asignaturas troncales comunes y algunas materias más convenientes y/o necesarias para alguna diócesis específica. 
Los seminaristas han de superar la tentación de quedarse en la diócesis principal donde se han formado y no volver. Este peligro se ha de subsanar con un planteamiento serio entre los distintos obispos a cuyas diócesis pertenezcan los seminaristas que comparten el mismo seminario y un plan de preparación pastoral que les vaya arraigando progresivamente en su propia diócesis, que no suponga sólo el decir «amo a mi diócesis», sino que sea un mostrar amor efectivo, sabiendo que la intensidad del amor a la parcela del pueblo a la que se está destinado para cuidarla es «amor a la Iglesia universal».

En todo caso, si existe Teologado donde residen los seminaristas, ha de estar dirigido por sacerdotes diocesanos.

Se debe cuidar que las prácticas pastorales de los fines de semana se realicen en la propia diócesis siempre que ello resulte posible. Esto es incuestionable. Esas prácticas ayudan a que se tenga conocimiento de las personas que forman la comunidad creyente y también propician el amor a ellas y la sintonía con sus problemas, sean estos grandes o pequeños, pues son los que a ellos les preocupan. Deben elegirse con mucho cuidado los sacerdotes, las tareas y los lugares donde ejerzan este cuasiministerio pastoral.

También los seminaristas han de fortalecer la pastoral vocacional al ministerio sacerdotal en la propia diócesis. Es muy importante, y lo que más entusiasma y decide a los niños y jóvenes, percibir la alegría, el entusiasmo por la respuesta. La capacidad de sintonía con ellos, el manifestarse como un joven de su tiempo, pero lleno del amor a Dios y al ministerio al que le invita, con un ejercicio claro de la libertad. Así, si promueven alguna actividad -convivencias, retiros, encuentros de fin de semana, campamentos...- responderán jóvenes y/o adolescentes que hayan sentido esa presencia de Dios en el talante de la vida normal de un seminarista. A esto denomina Amedeo Cencini «pastoral vocacional por contagio, porque estás lleno del amor y la alegría de Dios».

Se ha de promover con mucha fuerza la relación de los seminaristas con sacerdotes, personas consagradas y seglares diocesanos. Conscientes de que la comunidad no son solo ellos, sino que han de integrarse en todas aquellas personas que se comprometen en la misión, aportando los propios carismas. Sabemos, como afirma el apóstol Pablo, que los carismas están al servicio de la comunidad, y que la diversidad y abundancia de ellos enriquece personalmente a los seminaristas y les abre perspectivas más universales. 


\section{CONCLUSIÓN}

En general, si el número de seminaristas es tal que se pueda impartir una formación enriquecedora, es decir, que no impulse al «ombliguismo», que permita una visión universal y un número propio para los estudios, pueden permanecer en las respectivas diócesis. Ahora bien, si son pocos los seminarios que tienen suficiente número de vocaciones para mantenerse como válida plataforma educativa, lo mejor es que, sopesando elementos positivos y negativos, buscando el bien de los muchachos y de las diócesis, se proyecte un plan Interdiocesano que haga que nadie se considere extraño y pueda contrastar la propia vocación con otros.

Existen tantos elementos positivos que, pese a las debilidades, estos seminarios serán en un futuro próximo la solución para muchas diócesis. 